\title{
2014 Semi-Annual Progress Letter Report on Used Nuclear Fuel Integrity Study in Transportation Environments
}

April 2014

Prepared by

Jy-An John Wang and Hong Wang

Materials Science and Technology Division

Bruce B. Bevard and Rob Howard

Project Manager

Reactor \& Nuclear Systems Division

Oak Ridge National Laboratory

Approved for public release;

distribution is unlimited.

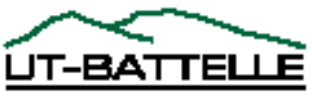

ORNL-27 (4-00) 


\section{DOCUMENT AVAILABILITY}

Reports produced after January 1, 1996, are generally available free via the U.S. Department of Energy (DOE) Information Bridge.

Web site http://www.osti.gov/bridge

Reports produced before January 1, 1996, may be purchased by members of the public from the following source.

National Technical Information Service

5285 Port Royal Road

Springfield, VA 22161

Telephone 703-605-6000 (1-800-553-6847)

TDD 703-487-4639

Fax 703-605-6900

E-mail info@ntis.fedworld.gov

Web site http://www.ntis.gov/support/ordernowabout.htm

Reports are available to DOE employees, DOE contractors, Energy

Technology Data Exchange (ETDE) representatives, and International Nuclear Information System (INIS) representatives from the following source.

Office of Scientific and Technical Information

P.O. Box 62

Oak Ridge, TN 37831

Telephone 865-576-8401

Fax 865-576-5728

E-mail reports@adonis.osti.gov

Web site http://www.osti.gov/contact.html

This report was prepared as an account of work sponsored by an agency of the United States Government. Neither the United States government nor any agency thereof, nor any of their employees, makes any warranty, express or implied, or assumes any legal liability or responsibility for the accuracy, completeness, or usefulness of any information, apparatus, product, or process disclosed, or represents that its use would not infringe privately owned rights. Reference herein to any specific commercial product, process, or service by trade name, trademark, manufacturer, or otherwise, does not necessarily constitute or imply its endorsement, recommendation, or favoring by the United States Government or any agency thereof. The views and opinions of authors expressed herein do not necessarily state or reflect those of the United States Government or any agency thereof. 


\title{
Progress Letter Report on Used Nuclear Fuel Integrity Study in Transportation Environments
}

\author{
Jy-An John Wang \\ Hong Wang \\ Materials Science and Technology Division \\ Bruce B. Bevard \\ Rob Howard \\ Project Manager \\ Reactor \& Nuclear Systems Division \\ Oak Ridge National Laboratory
}

Date Published: July 2013
Prepared by
OAK RIDGE NATIONAL LABORATORY
P.O. Box 2008
Oak Ridge, Tennessee 37831-6285
managed by
UT-BATTELLE, LLC
for the
U.S. DEPARTMENT OF ENERGY
under contract DE-AC05-00OR22725




\section{Contents}

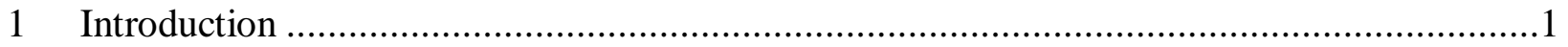

2 Development of Hardware and Software .................................................................

3 Probe Effect Study on Curvature Measurement .............................................................5

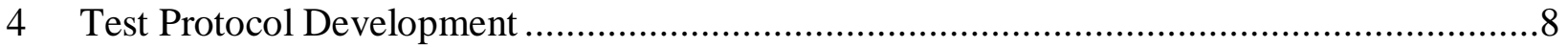

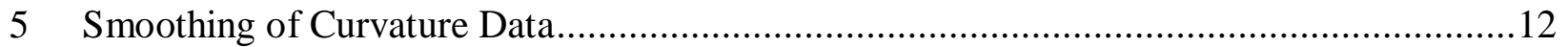

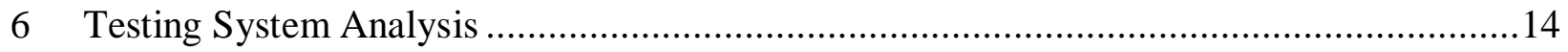

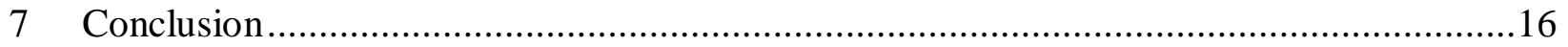

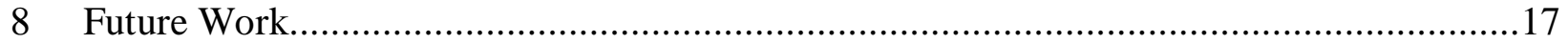

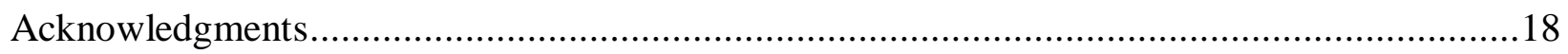

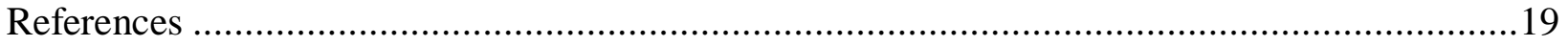




\section{List of Figures}

Figure 1 Bose dual LM2 TestBench Installed at L218, ORNL HTML 4515 ............................2

Figure 2 (a) Front and (b) back view of assembled U-frame to Bose dual LM2 TestBench.........3

Figure 3 (a) Front and (b) back view of power modular, PCI control, and LM2 LVDT amplifiers.

Figure 4 (a) Amplifier, power supply, calibration setup of three curvature LVDTs, and (b) the integrated channels of LM2 load cells, LM2 LVDTs, and three curvature LVDTs into Bose PCI

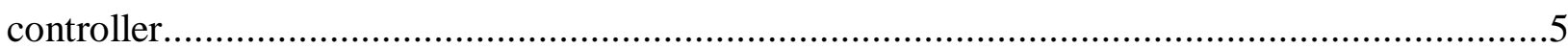

Figure 5 Calibration results of LVDT 607 with DR7AC 359..............................................5 Figure 6 Diagrams showing the deflections measured by LVDTs may be at different points from

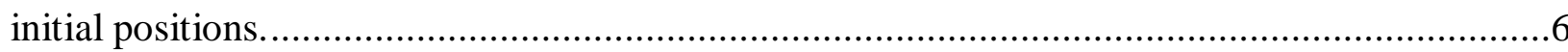

Figure 7 (a) Three curvature LVDTs were being held against the rod, (b) LVDT clamp was open to show (a) flat probe in one configuration and (b) chisel probe in another configuration............7 Figure 8 (a) Moment and (b) curvatures based on results with relative displacement $1.0 \mathrm{~mm}$,

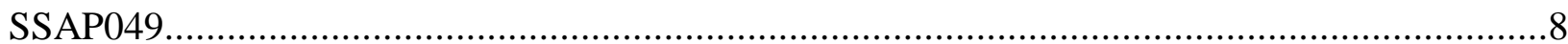

Figure 9 Curvature range corrected as a function of contact diameter under various relative

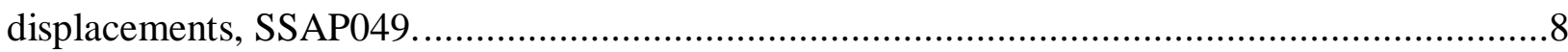
Figure 10 No significant changes in response of rod observed between (a) procedure 1 and (b) procedure 2 for chisel contact, SSAP049.

Figure 11 No significant changes in response of rod observed between (a) procedure 1 and (b) procedure 3 for chisel contact, SSAP049.

Figure 12 No significant discontinuity was observed near stops on curvature variation for (a) zero-N end-level control and (b) zero-mm end-level control.

Figure 13 (a) Moment and (b) curvature data smoothed by using a cubic 15-piece approximation function. The results were based on DM2 hot cell testing.

Figure 14 (a) Noisy and (b) de-noised moment-curvature curve........................................13

Figure 15 (a) Enlarged initial stage of LVDT1 data, and (b) the data block obtained in one measurement session. The results were based on DM2 testing.

Figure 16 (a) Measurement with noise and with noise removed, and (b) the same measurement after resetting the smoothed three LVDT channels and smoothing the curvature.

Figure 17 (a) Applied moment and (b) curvature based on test at 1Hz, SS30402. Smoothing has been applied to both signals. One-period data block was used in characterization....................15 Figure 18 Scatter plot of moment range vs. curvature range based on the first run, SS30402....15 Figure 19 Gain as a function of frequency based on results of SS30402...............................16 


\section{List of Tables}

Table 1 Three test procedures were evaluated: 1) cycle w/o stop, 2) cycle w/ stop but no channel reset, 3) cycle w/ stop and channel reset. ...................................................................8 Table 2 New test procedure with zero-N end-level control was tested using chisel contact. Relative displacement control has to be used in measurement step. .....................................11 


\section{Introduction}

The objective of this project is to perform a systematic study on UNF (Used Nuclear Fuel) integrity under simulated transportation environments by using enabling hot-cell testing technology developed recently at ORNL, CIRFT (Cyclic Integrated Reversible-Bending Fatigue Tester) [1-9]. Out-of-cell study will support the ongoing ORNL hot-cell or in-cell testing. Although the use of CIRFT on $\mathrm{H}$. B. Robinson UNF rods generated many interesting data, a number of important issues remain to be addressed arising from the test system and the rod itself. It has been shown that a direct examination of some of these issues in the hot-cell is prohibitive due to high cost and access limitations. The out-of-cell study has been demonstrated to be costeffective and much more feasible to provide quick turn-around solutions. A testing system with the same configuration as that of CIRFT used in hot-cell has been proposed to study the emerging issues from hot-cell testing and also to investigate the fatigue and failure mechanisms of UNF rods that cannot be identified directly with in hot-cell testing. The developments of hardware and software, test protocol, and hot-cell data analysis will be discussed in this report.

\section{Development of Hardware and Software}

Purchase of the second Bose dual LM2 TestBench was started in April of 2013. ORNL considered two options of Bose dual linear motor test bench in the initial stage.

- Option 1- be based on LM2, 2 X 3000N, +/-12.5mm, with the configuration the same as the one now being used in the hot-cell; namely, one reactive bracket, one breadboard, two 3000N load cells, two 12.5mm LVDTs, 8 input/4 output controller system, PC/monitor and WinTest software.

- Option 2- be based on LM3, 2 X 7500N, +/-25mm, with similar configuration to the first one in which load cells and LVDTs will be changed accordingly.

The main purpose of looking at the LM3 was to try to get a large stroke. However, according to Bose, the design of the LM3 motor prohibits horizontal mounting of that unit and it cannot be made into a horizontal TestBench configuration. ORNL decided to pursue the LM2-based as the second Bose linear motor TestBench in May of 2013. This was quoted by Bose on May 72013 (20089487), and after the purchase justification, a purchase requisition (3400189204) was established within the ORNL procurement system on Jun 18, 2013. The P.O. (4000123731) was finally released to Bose on June 24, 2014 after two more rounds of ORNL internal ES\&H reviews and approvals.

Numerous discussions occurred between ORNL and Bose after the purchase release with regard to the modification to include Rad-hardened LVDTs, load cells, a central panel for overall cable and wire integration, and another panel for the wire integration of three curvature LVDTs. The purpose of these modifications was to make the testing system hot-cell ready. The final 
agreement was reached between ORNL and Bose to build the second Bose machine under the same configuration as that of the first one; this is because the integration of the proposed central panels had been shown to be prohibitive in terms of both cost and time. The Bose machine was acquired on September 24 of 2013. The test bench was installed as shown in Figure 1 and then checked by a Bose engineer in early October, 2013.

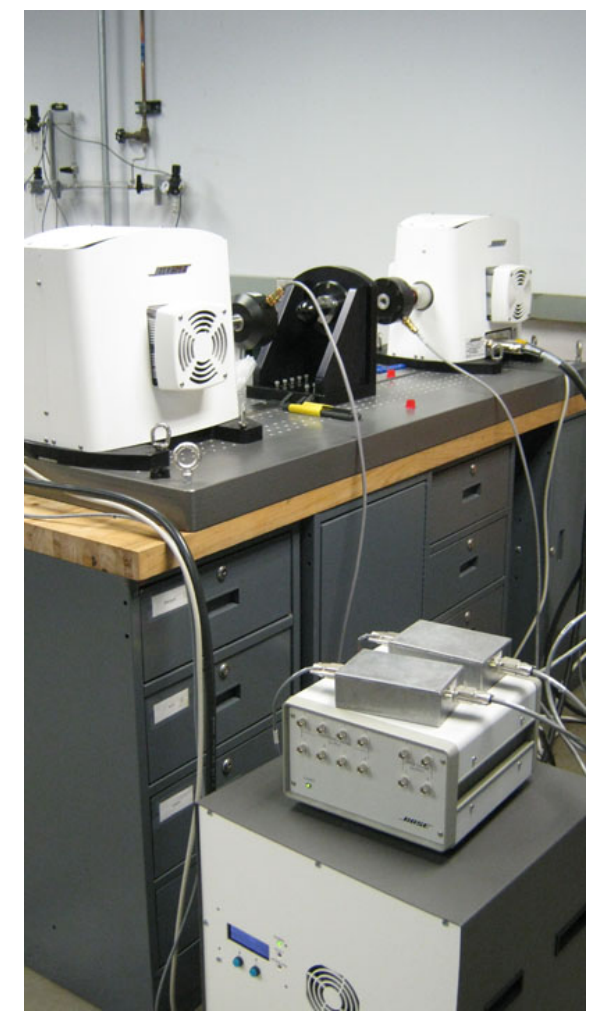

Figure 1 Bose dual LM2 TestBench Installed at L218, ORNL HTML 4515

A request to fabricate U-frame components was sent out on June 11, 2013, and East Tennessee Machine was selected on Jun 28, 2013 after a machining solicitation. Because of several priority jobs placed for hot-cell testing at the same machine shop, the fabrication job on U-frame components was delayed but delivered in the middle of September 2013. Some of the parts were found not to be machined according to the drawings in a preliminary check and re-worked. A subsequent assembly process revealed additional corrections were needed. The second CIRFT was assembled in early December, 2013 after the corrected parts had been received. The system consists of dual LM2 Bose TestBench and U-frame testing setup and is equipped with three LVDTs to measure deflections at three points for curvature measurement. Two $3000 \mathrm{~N}$ load cells and two 12.5 mm LVDTs are used in the Bose machine for control and measurement. The U- 
frame has a $101.60 \mathrm{~mm}$ loading arm, and three curvature LVDTs have $\pm 5 \mathrm{~mm}$ measurement range. The overall setup, power module, PCI-82 controller, three curvature LVDT amplifiers and power supplies are shown in Figure 2, Figure 3, and Figure 4. One of RDP D5/200AG-337 $( \pm 5 \mathrm{~mm})$ LVDTs is waiting for replacement due to damaged component. And three D6 $( \pm 2.5 \mathrm{~mm})$ LVDTs were then used in the current testing setup. They were calibrated and integrated into Bose PCI-82. The calibration results are given in Figure 5 for one of LVDTs.

The tuning using a surrogate rod demonstrated the system run quite stably. Several warning lines appeared during the tests, and Bose was contacted for debugging. The related test files were sent back to Bose and have been corrected.

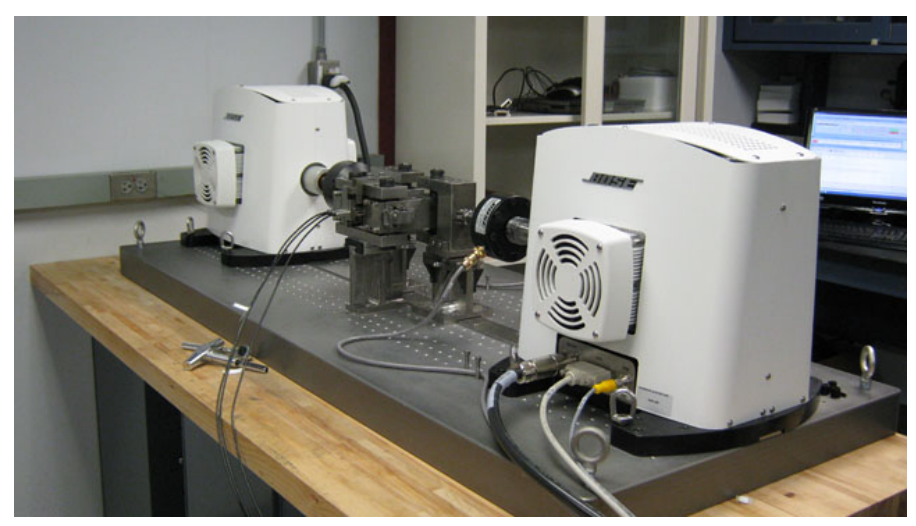

(a)

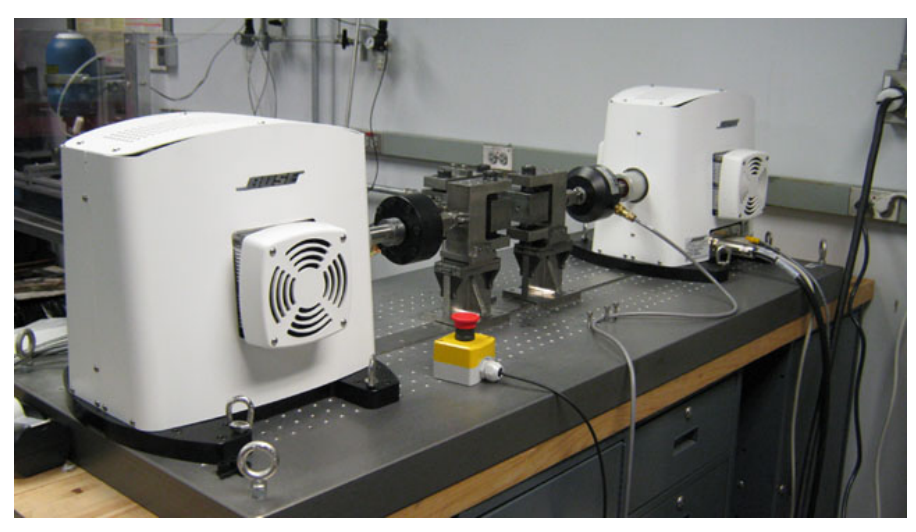

(b)

Figure 2 (a) Front and (b) back view of assembled U-frame to Bose dual LM2 TestBench 


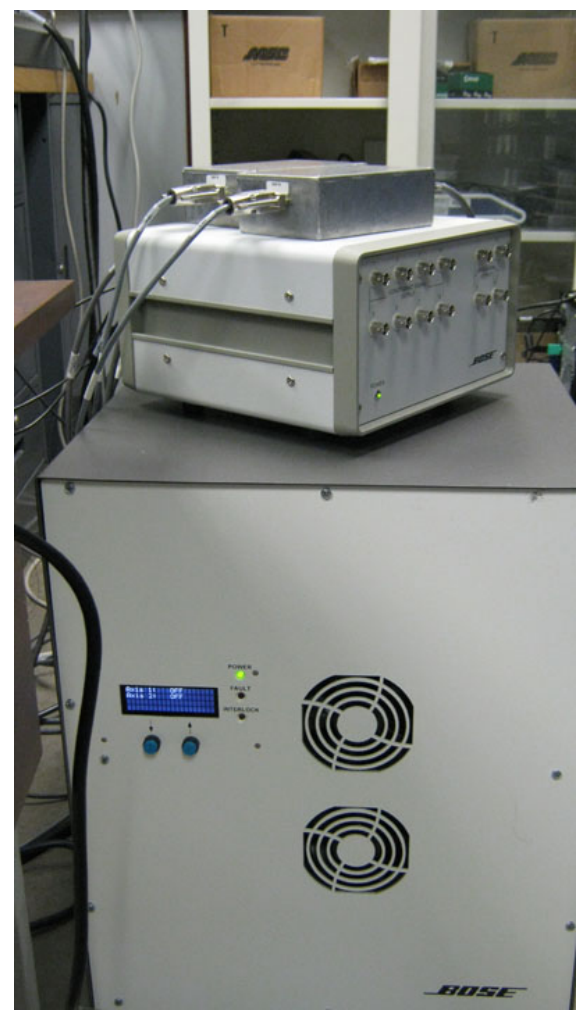

(a)

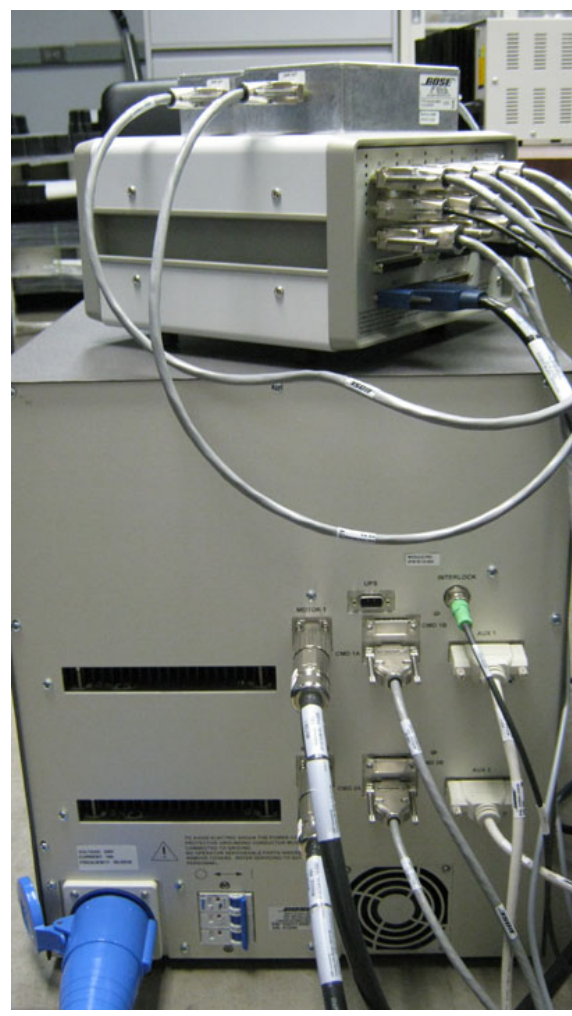

(b)

Figure 3 (a) Front and (b) back view of power module, PCI control, and LM2 LVDT amplifiers.

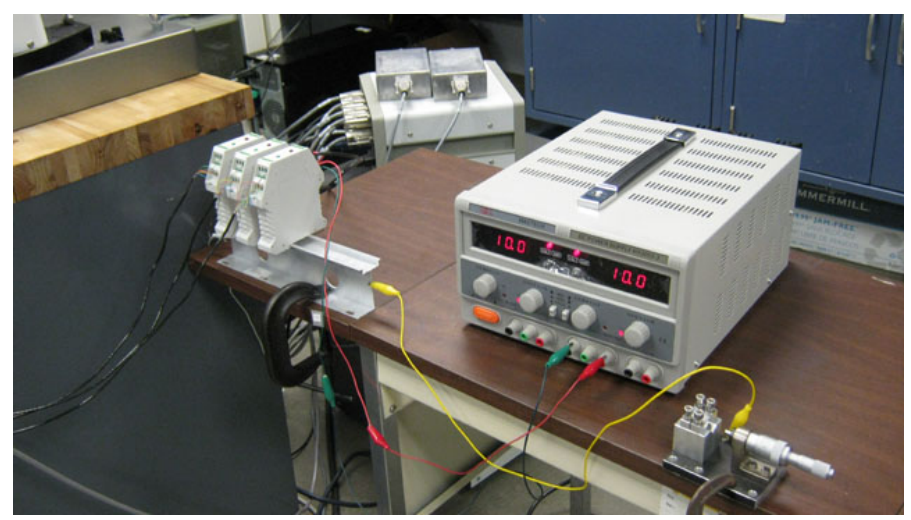

(a) 


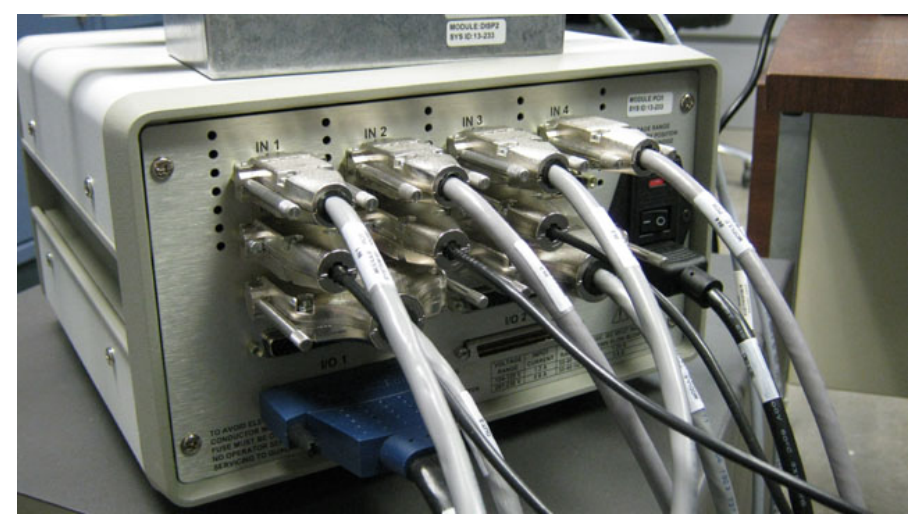

(b)

Figure 4 (a) Amplifier, power supply, calibration setup of three curvature LVDTs, and (b) the integrated channels of LM2 load cells, LM2 LVDTs, and three curvature LVDTs into Bose PCI controller.

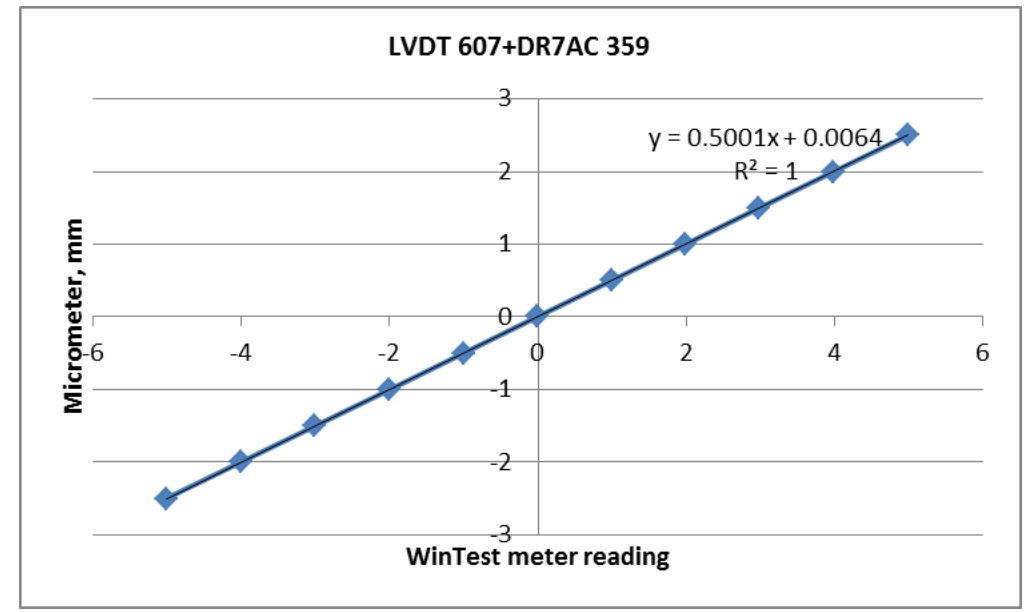

Figure 5 Calibration results of LVDT 607 with DR7AC 359.

\section{Probe Effect Study on Curvature Measurement}

There was a serious concern with the effect of the probe on the curvature measurement of the rod, especially when the load amplitude becomes small. This is mainly because the contact of the probe may be shifted when the bending direction changes. It is believed that such the effect of probe can be considered by using the sensor space, h, as shown in Figure 6, which depends on the contact diameter. 


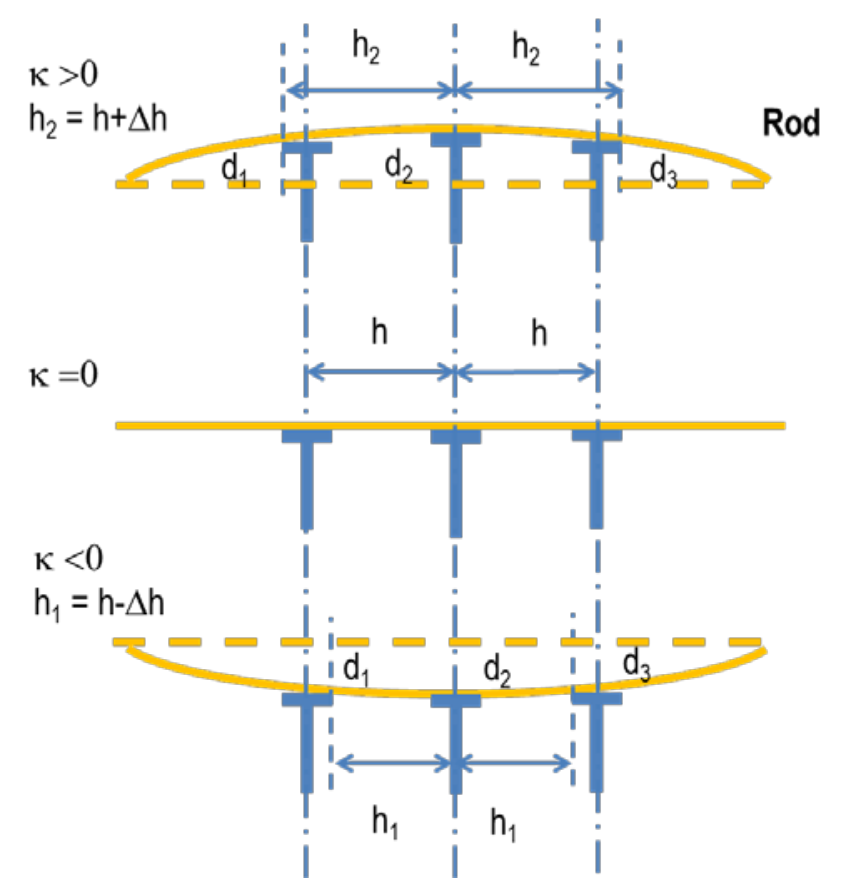

Figure 6 Diagrams showing the deflections measured by LVDTs may be at different points from initial positions.

The probe study was carried out by using SSAP049 with both flat disk contact and chisel contact (Figure 7). Small amplitude low-frequency measurements were conducted in which loads were controlled so that the irreversible deformation of rod can be negligible and results can be compared. The tests under \pm 0.3 to $0.5 \mathrm{~mm}$ showed that the difference in curvature responses of rod measured by two types of probes is relatively small; one of test cases is shown in Figure 8. Moment-curvature plots further showed a slightly left shift ( 7.7\% in high end) when the chisel contact was used. The observation suggests that the correction of probe effect might not properly work here, even though the current probe study is limited to one surrogate rod. For example, substituting a contact diameter of $6 \mathrm{~mm}$ into the probe model would results in $\sim 22 \%$ increase in curvature range given $1.0 \mathrm{~mm}$ relative displacement input (Figure 9). The use of $6 \mathrm{~mm}$ contact diameter apparently enhanced the fluctuation in fatigue response of flexural rigidity of rod. As a result, it is suggested that the data generated by using flat probe in hot cell test, for the time being, be processed without the correction. 


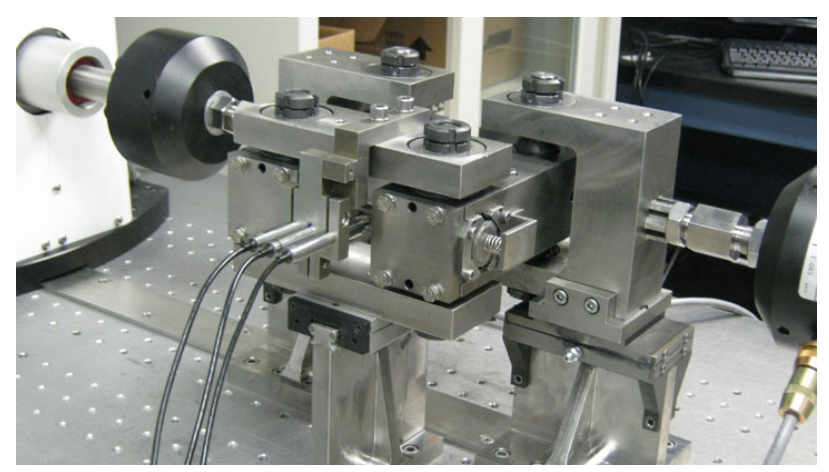

(a)

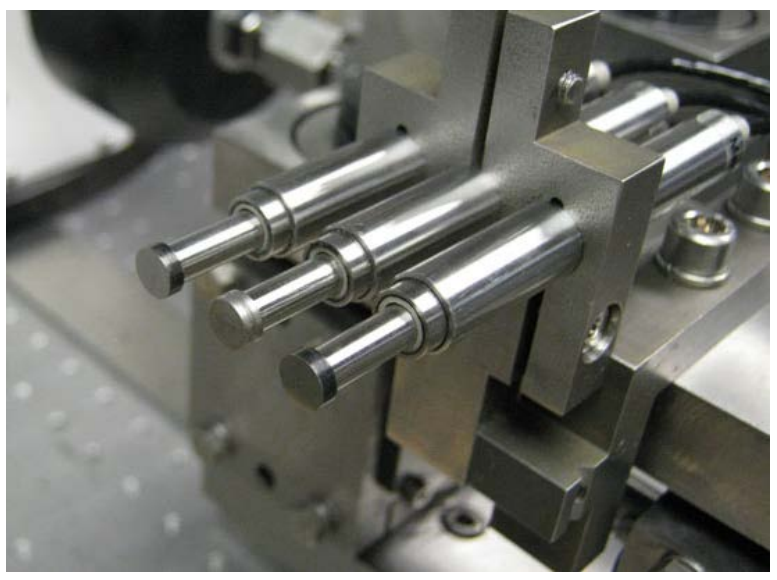

(b)

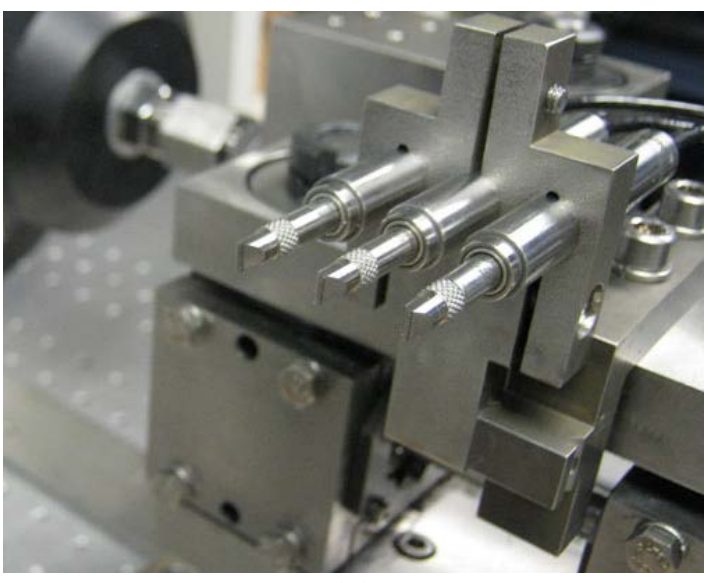

(c)

Figure 7 (a) Three LVDTs were being held against the rod, (b) LVDT clamp was opened to show (b) flat probe in one configuration and (c) chisel probe in another configuration.

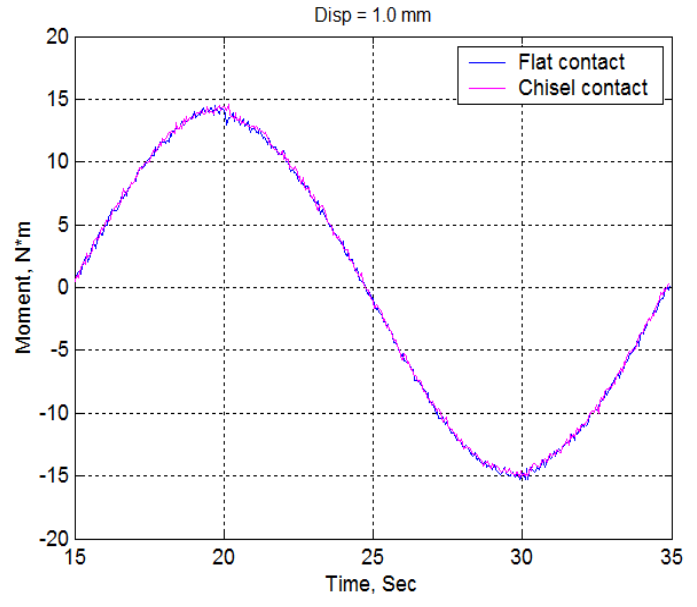

(a)

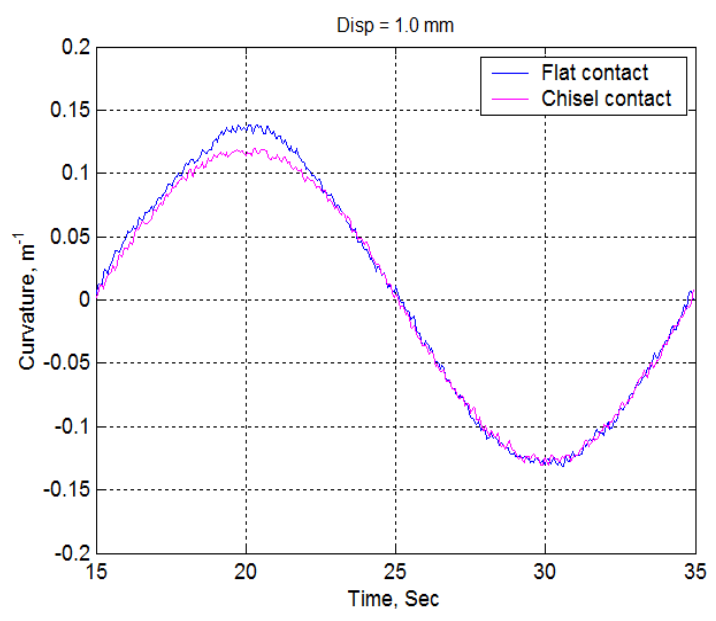

(b) 
Figure 8 (a) Moment and (b) curvatures based on results with relative displacement of $1.0 \mathrm{~mm}$, SSAP049.

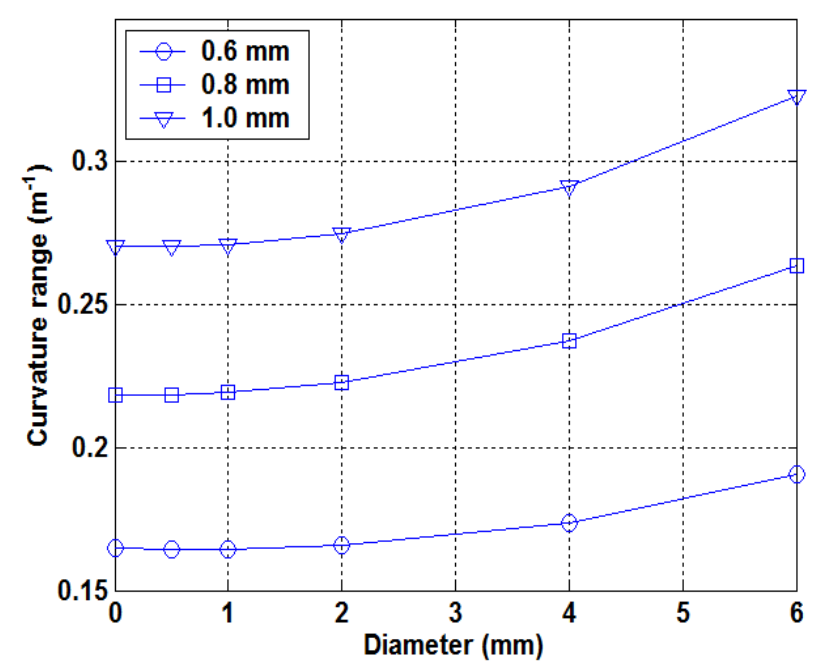

Figure 9 Curvature range corrected as a function of contact diameter under various relative displacements, SSAP049.

\section{Test Protocol Development}

Three test procedures were evaluated using SSAP049 at the same time including: 1) cycling without stop, 2) cycling with stop but no channel reset, 3) cycle with both stop and channel reset. $5 \mathrm{~Hz}$ frequency was used, while the load amplitude was controlled at a small level for the same reason mentioned above (Table 1). Again, both chisel and flat contacts were tested. It has been demonstrated that, under the tested condition, no significant change in curvature response of rod can be seen between procedure 1 and 2 (Figure 10), and between procedure 1 and 3 (Figure 11) for chisel contact. The same observation holds for the case of flat contact.

Table 1 Three test procedures were evaluated: 1) cycle w/o stop, 2) cycle w/ stop but no channel reset, 3) cycle w/ stop and channel reset.

\begin{tabular}{|l|l|l|l|l|l|l|l|}
\hline Date & No. & $\begin{array}{l}\text { pk1 } \\
(\mathrm{mm}, \\
\mathrm{N})\end{array}$ & $\begin{array}{l}\text { pk2 } \\
(\mathrm{mm}, \\
\mathrm{N})\end{array}$ & $\begin{array}{l}\text { Freq } \\
(\mathrm{Hz})\end{array}$ & Increment & $\begin{array}{l}\text { Total } \\
\text { cycles }\end{array}$ & Note \\
\hline $1 / 14 / 2014$ & 1 & -100 & 100 & 5 & 10000 & 10000 & chisel, no stop \\
\hline
\end{tabular}




\begin{tabular}{|l|l|l|l|l|l|l|l|}
\hline $1 / 14 / 2014$ & 2 & -100 & 100 & 5 & 1000 & 1000 & chisel, stop w/o reset \\
\hline $1 / 14 / 2014$ & 3 & -100 & 100 & 5 & 4000 & 5000 & chisel, stop w/o reset \\
\hline $1 / 14 / 2014$ & 4 & -100 & 100 & 5 & 5000 & 10000 & chisel, stop w/o reset \\
\hline $1 / 14 / 2014$ & 5 & -100 & 100 & 5 & 1000 & 1000 & chisel, stop w/ reset \\
\hline $1 / 14 / 2014$ & 6 & -100 & 100 & 5 & 4000 & 5000 & chisel, stop w/ reset \\
\hline $1 / 14 / 2014$ & 7 & -100 & 100 & 5 & 5000 & 10000 & chisel, stop w/ reset \\
\hline $1 / 17 / 2014$ & 41 & -100 & 100 & 5 & 10000 & 10000 & flat, no stop \\
\hline $1 / 17 / 2014$ & 42 & -100 & 100 & 5 & 1000 & 1000 & flat, stop w/o reset \\
\hline $1 / 17 / 2014$ & 43 & -100 & 100 & 5 & 4000 & 5000 & flat, stop w/o reset \\
\hline $1 / 17 / 2014$ & 44 & -100 & 100 & 5 & 5000 & 10000 & flat, stop w/o reset \\
\hline $1 / 21 / 2014$ & 45 & -100 & 100 & 5 & 1000 & 1000 & flat, stop w/ reset \\
\hline $1 / 21 / 2014$ & 46 & -100 & 100 & 5 & 4000 & 5000 & flat, stop w/ reset \\
\hline $1 / 21 / 2014$ & 47 & -100 & 100 & 5 & 5000 & 10000 & flat, stop w/ reset \\
\hline
\end{tabular}
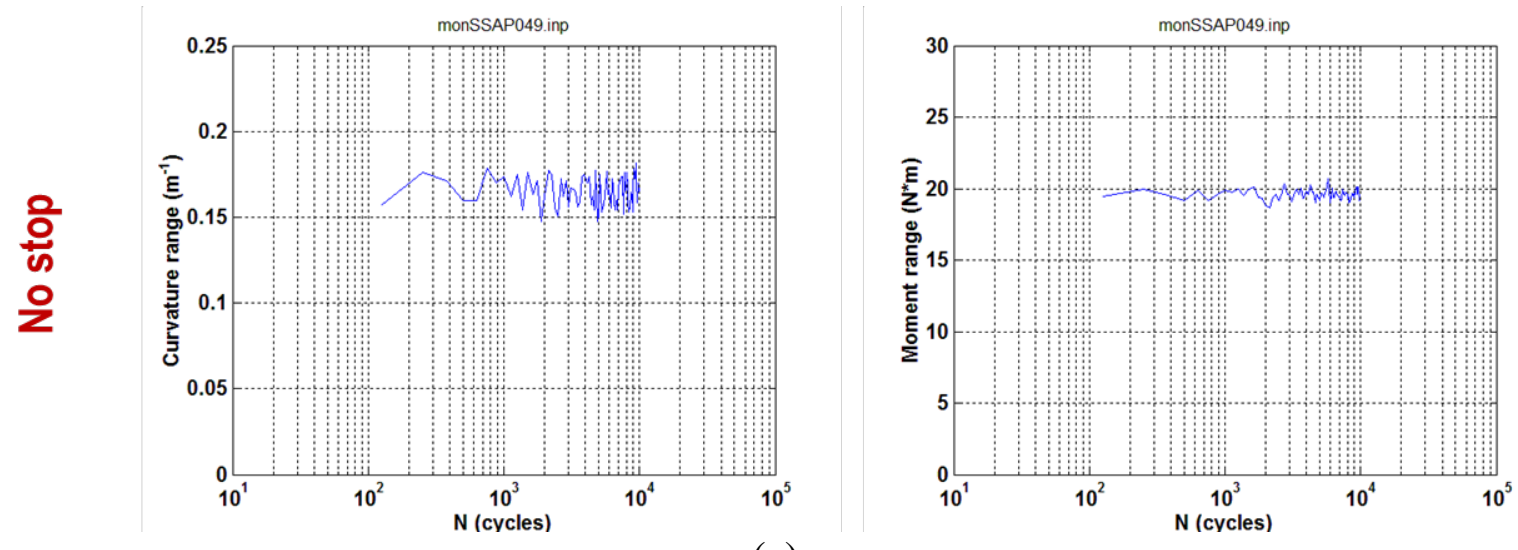

(a)
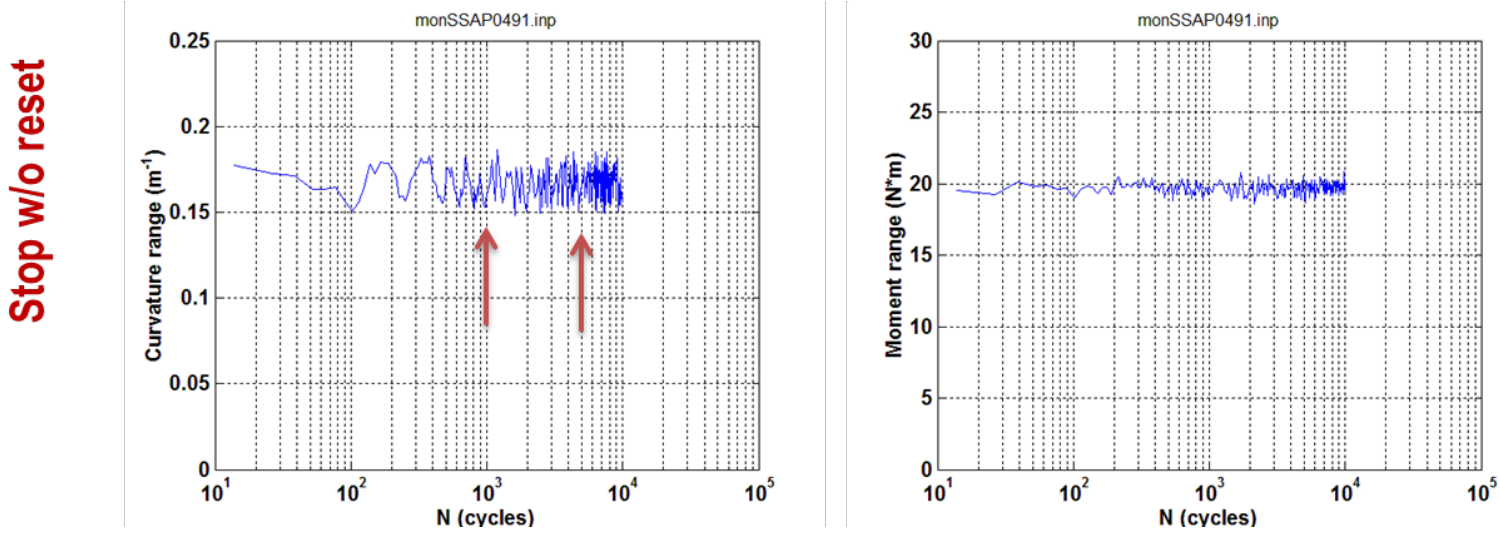

(b)

Figure 10 No significant changes in response of rod observed between (a) procedure 1 and (b) procedure 2 for chisel contact, SSAP049. The red arrows indicate the stop/restart positions. 

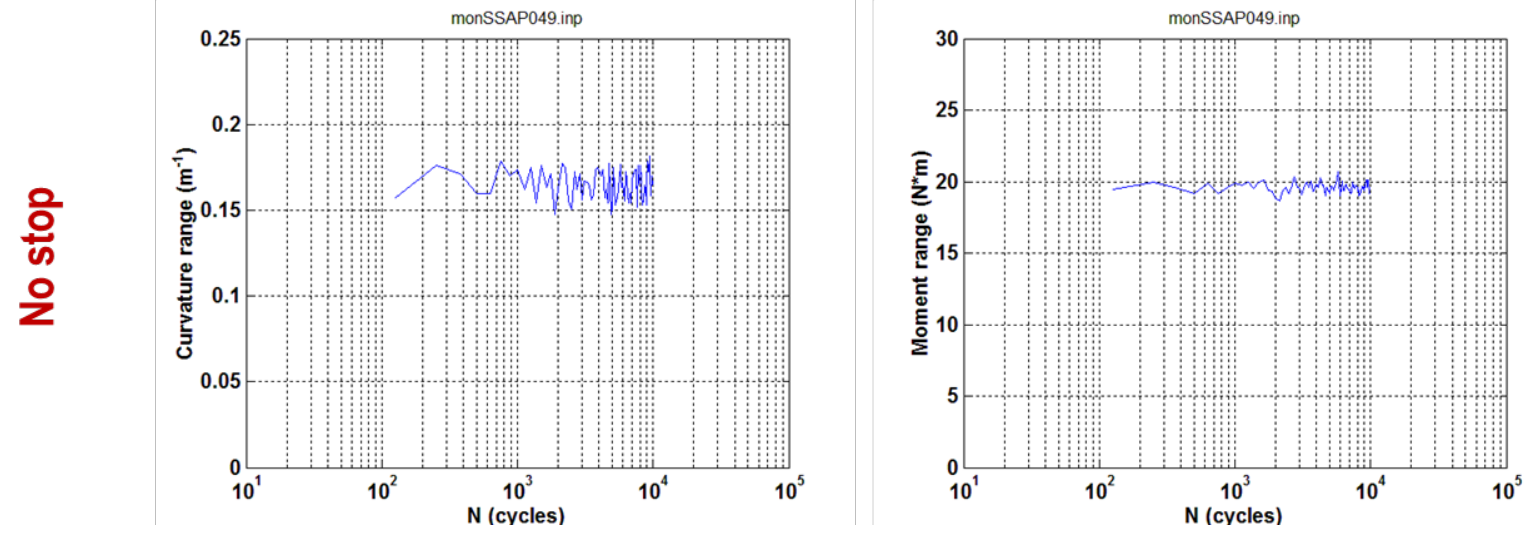

(a)
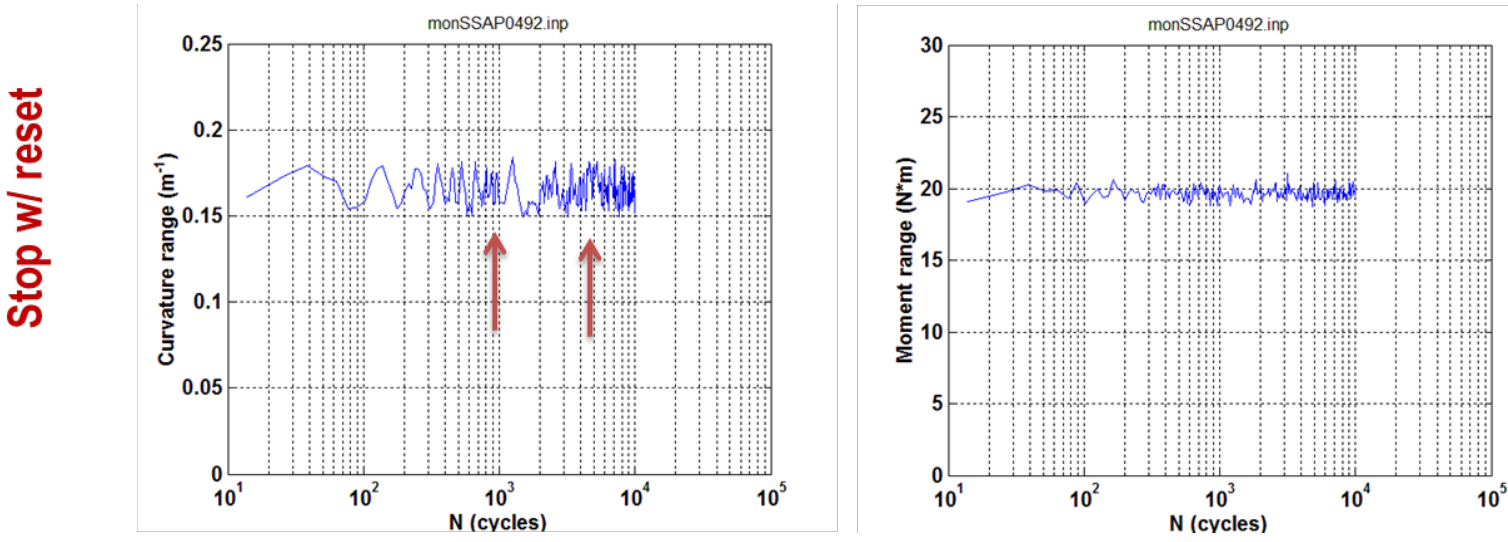

(b)

Figure 11 No significant changes in response of rod observed between (a) procedure 1 and (b) procedure 3 for chisel contact, SSAP049. The red arrows indicate the stop/restart positions.

At the same time, the zero-N end-level control was tested using SSAP049 to more than 100,000 cycles at $5 \mathrm{~Hz}$ (Table 2), in which the measurements were accomplished by using relative displacement control. Namely, the cyclic test was stopped at each designated number of cycles. The test results didn't show any significant discontinuity related to measurement stops on curvature variation. Thus, zero- $\mathrm{N}$ end-level control appears to be a feasible test procedure. The implementation of direct load control requires additional tuning, and use of zero-N ending-level control in hot-cell remains to be justified in next step. 
Table 2 New test procedure with zero-N end-level control was tested using chisel contact. Relative displacement control has to be used in measurement step.

\begin{tabular}{|l|l|l|l|l|l|l|l|}
\hline Date & No. & $\begin{array}{l}\text { pk1 } \\
(\mathrm{mm}, \mathrm{N})\end{array}$ & $\begin{array}{l}\text { pk2 } \\
(\mathrm{mm}, \mathrm{N})\end{array}$ & $\begin{array}{l}\text { Freq } \\
(\mathrm{Hz})\end{array}$ & Increment & $\begin{array}{l}\text { Total } \\
\text { cycles }\end{array}$ & Note \\
\hline $1 / 16 / 2014$ & 29 & -100 & 100 & 5 & 1000 & 1000 & zero N \\
\hline $1 / 16 / 2014$ & 30 & -0.3 & 0.3 & 0.05 & 3 & 1000 & rel. displacement \\
\hline $1 / 16 / 2014$ & 31 & -0.4 & 0.4 & 0.05 & 3 & 1000 & rel. displacement \\
\hline $1 / 16 / 2014$ & 32 & -0.5 & 0.5 & 0.05 & 3 & 1000 & rel. displacement \\
\hline $1 / 16 / 2014$ & 33 & -100 & 100 & 5 & 10000 & 11000 & zero N \\
\hline $1 / 16 / 2014$ & 34 & -0.3 & 0.3 & 0.05 & 3 & 11000 & rel. displacement \\
\hline $1 / 16 / 2014$ & 35 & -0.4 & 0.4 & 0.05 & 3 & 11000 & rel. displacement \\
\hline $1 / 16 / 2014$ & 36 & -0.5 & 0.5 & 0.05 & 3 & 11000 & rel. displacement \\
\hline $1 / 16 / 2014$ & 37 & -100 & 100 & 5 & 100000 & 111000 & zero N \\
\hline $1 / 17 / 2014$ & 38 & -0.3 & 0.3 & 0.05 & 3 & 111000 & rel. displacement \\
\hline $1 / 17 / 2014$ & 39 & -0.4 & 0.4 & 0.05 & 3 & 111000 & rel. displacement \\
\hline $1 / 17 / 2014$ & 40 & -0.5 & 0.5 & 0.05 & 3 & 111000 & rel. displacement \\
\hline
\end{tabular}
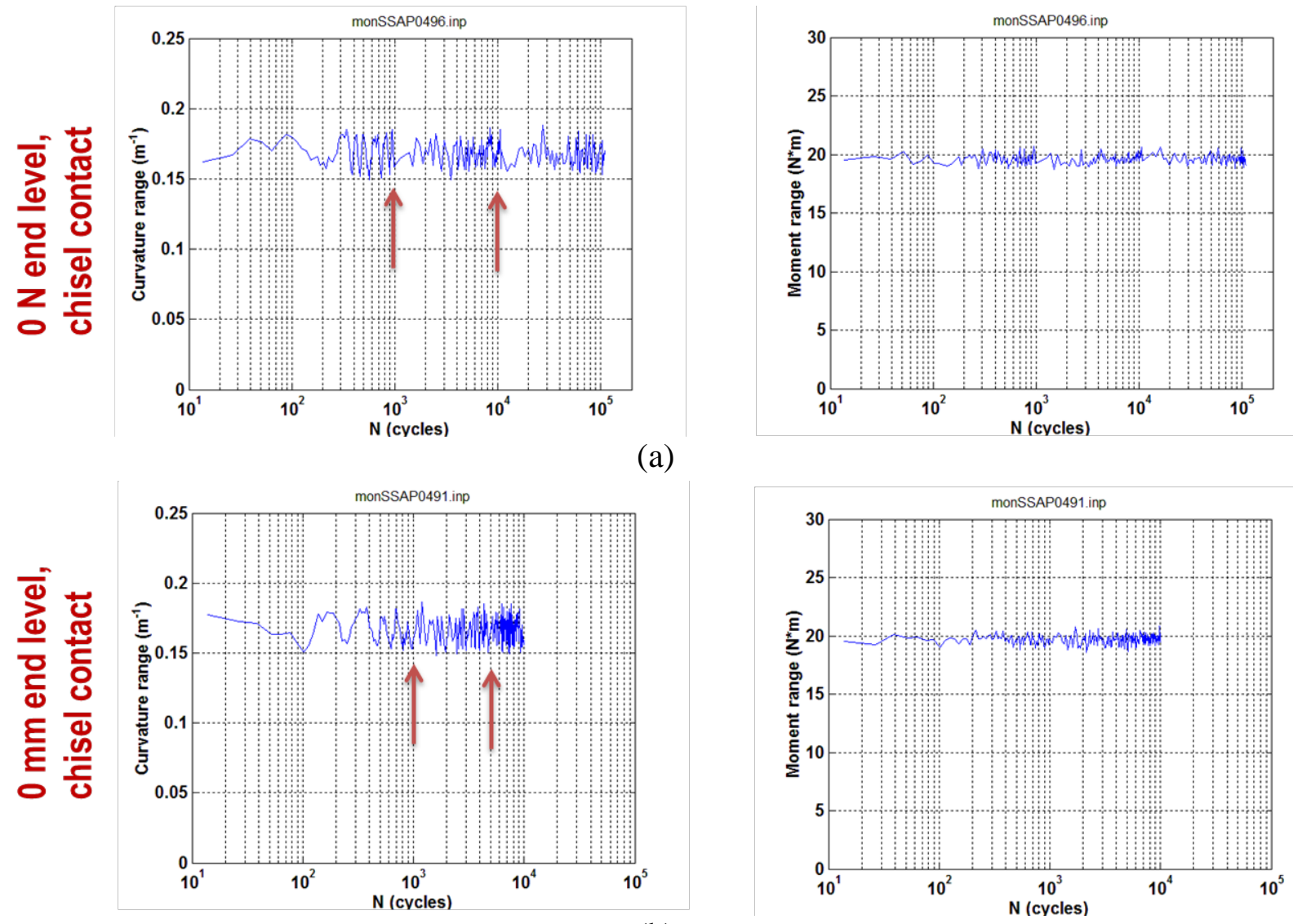

(b)

Figure 12 No significant discontinuity was observed near stops on curvature variation for (a) zero-N end-level control and (b) zero-mm end-level control. 


\section{Smoothing of Curvature Data}

The three LVDT-based curvature appeared extremely noisy in hot-cell testing. The high noise level involved makes the required information hardly resolved, especially when the load amplitude of cyclic test becomes small.

The low-frequency measurement data on DM2 in hot- cell testing were studied by using a least square splice smoothing function. Particularly, a MATLAB-based cubic 15-piece approximation function was used to smooth a 70-second data block obtained in measurement at $0.05 \mathrm{~Hz}$. The data processing procedure consists of the following steps:

1) Smooth the moment data,

2) Smooth the three LVDT signals,

3) Reset the three LVDT channels after the smoothed,

4) Calculate the curvature based on the reset three LVDTs, and

5) Smooth the curvature data.

Preliminary smoothed moment and curvature and their loops are given in Figure 13 and Figure 14, respectively. It has been demonstrated that re-setting the LVDT channel in WinTest may not be effectively implemented because of large noise level. The LVDT channel was triggered at the level when loading was started, but that level was different from what was reset as seen in the case of LVDT1 (Figure 15). Therefore, the reset to the true mean level based on the smoothed LVDT signal is necessary in the data processing stage. The effect of resetting LVDTs and smoothing can be seen clearly from loops in Figure 16. The moment-curvature curve can be resolved.

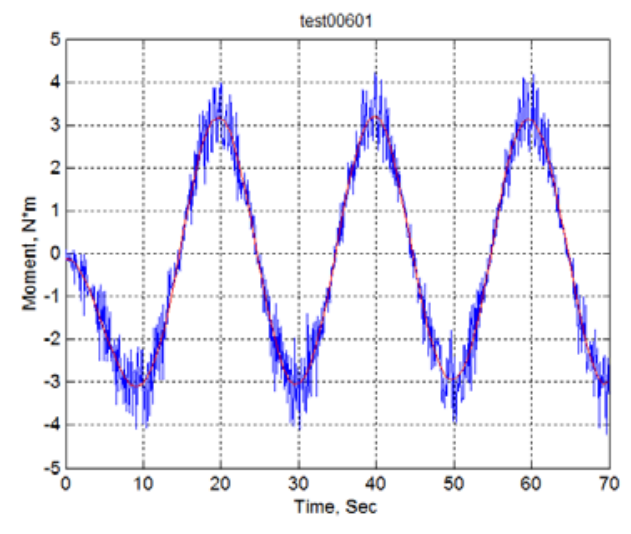

(a)

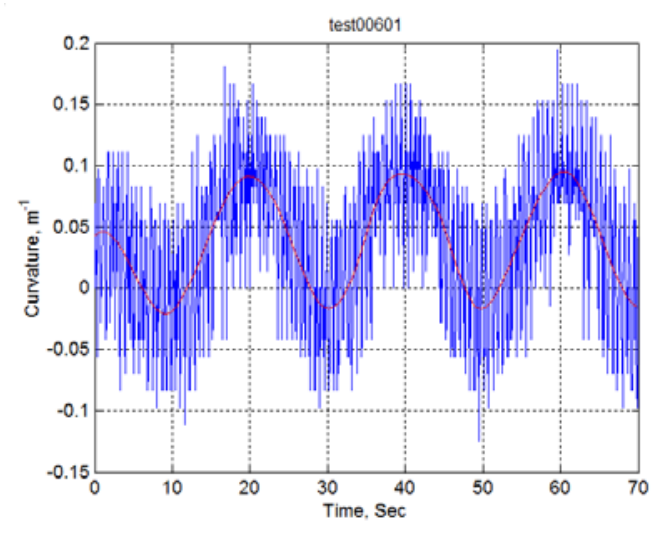

(b)

Figure 13 (a) Moment and (b) curvature data smoothed by using a cubic 15-piece approximation function. The results were based on DM2 hot cell testing. 


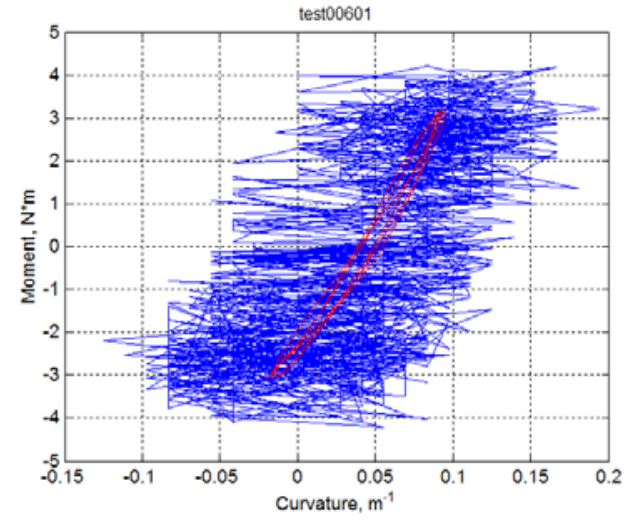

(a)

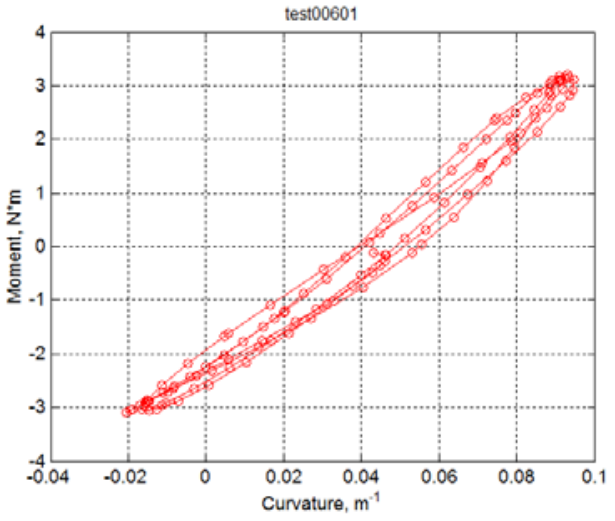

(b)

Figure 14 (a) Noisy and (b) de-noised moment-curvature curve.

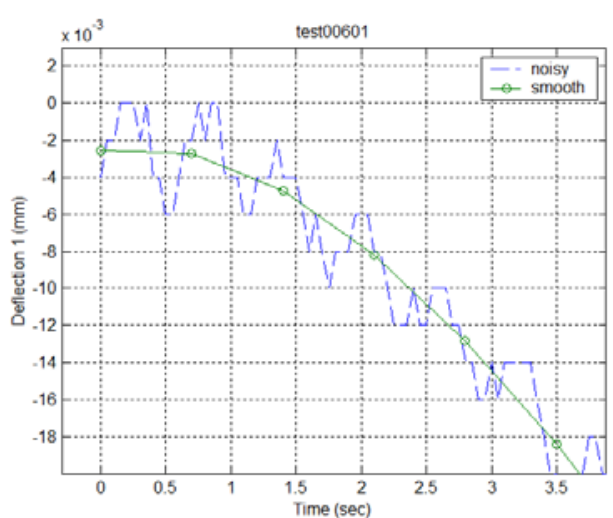

(a)

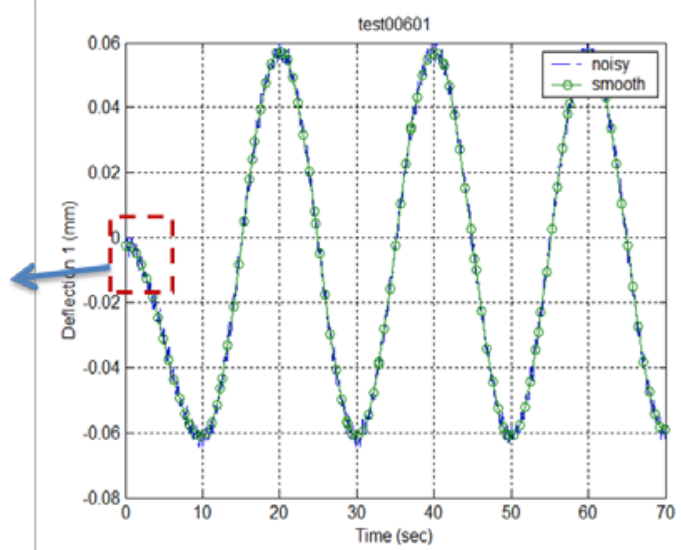

(b)

Figure 15 (a) Enlarged initial stage of LVDT1 data, and (b) the data block obtained in one measurement session. The results were based on DM2 testing. 


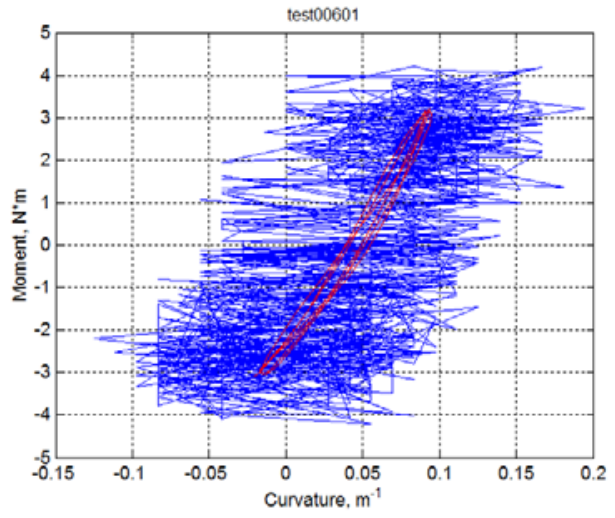

(a)

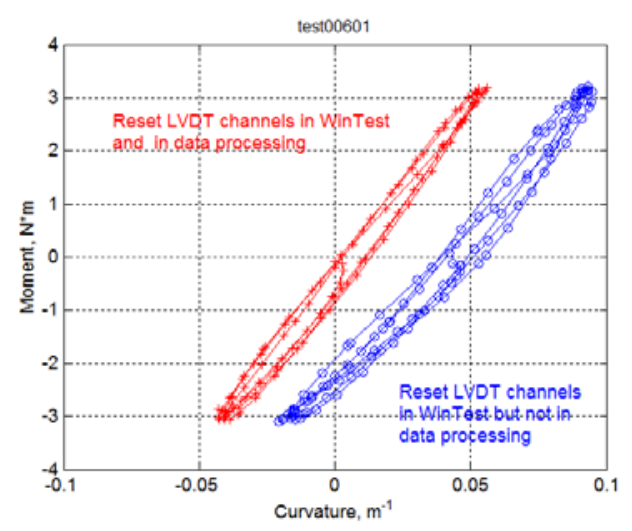

(b)

Figure 16 (a) Measurement with noise and with noise removed, and (b) the same measurement after resetting the smoothed three LVDT channels and smoothing the curvature.

\section{Testing System Analysis}

The resistance of system components to driving of dual linear motors becomes a major concern, especially when the need exists on small amplitude cyclic testing in hot-cell. The effect of resistive force on the response of the rod was tested by using a surrogate rod for the first CIRFT before the delivery. The data were re-analyzed in this reported period.

The surrogate rod SS30402 was made of a SS304 tube with ID $7.874 \mathrm{~mm}$, OD $9.563 \mathrm{~mm}, \mathrm{E}=$ $193 \mathrm{GPa}$, and $\mathrm{EI}=42.8 \mathrm{Nm}^{2}$. The tests were conducted under $\pm 100 \mathrm{~N}, 1$ to $10 \mathrm{~Hz}$ to evaluate the response of the system. Two runs of the tests were carried out to examine the repeatability of data. One set of input-output is shown in Figure 17, and part of the data was smoothed and then used in the evaluation. The curvature range as response of input moment is given in Figure 18. Because the rigidity of the rod, EI, is given, the curvature can be converted into the moment applied to the rod easily. Therefore, the moment applied to the rod and that applied to the Uframe can be correlated. The results are expressed in terms of gain, namely, ratio of moments of the rod to the U-frame as shown in Figure 19. It can be seen that the data are quite repeatable and the gain is close to one around $5 \mathrm{~Hz}$ that is being used in the hot-cell cyclic test. A thorough understanding of the system is needed to confirm the observations. 


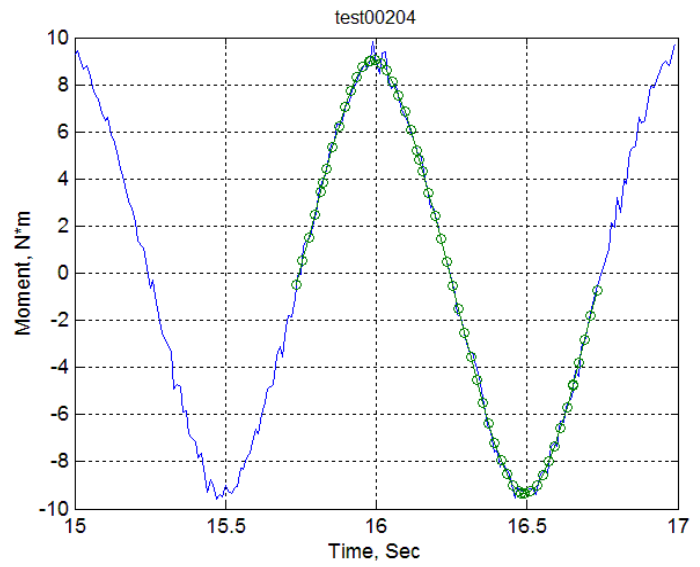

(a)

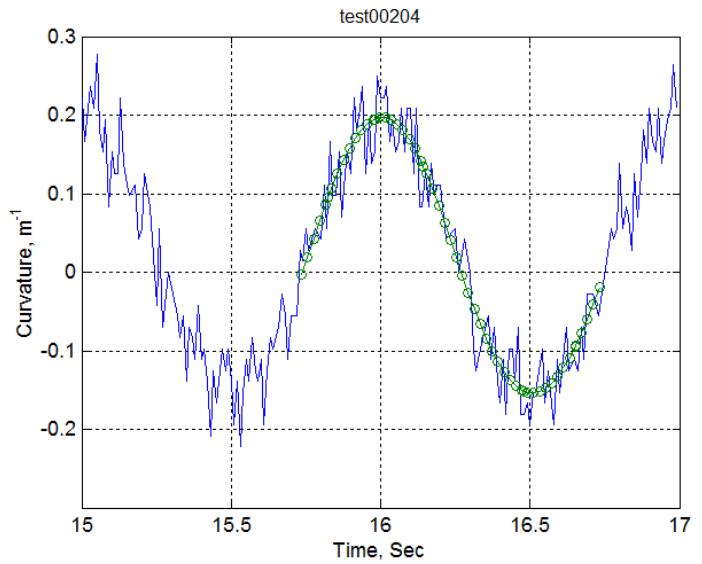

(b)

Figure 17 Smoothing has been applied to both moment and curvature signals, as shown (a) applied moment and (b) curvature based on test at 1Hz, SS30402.

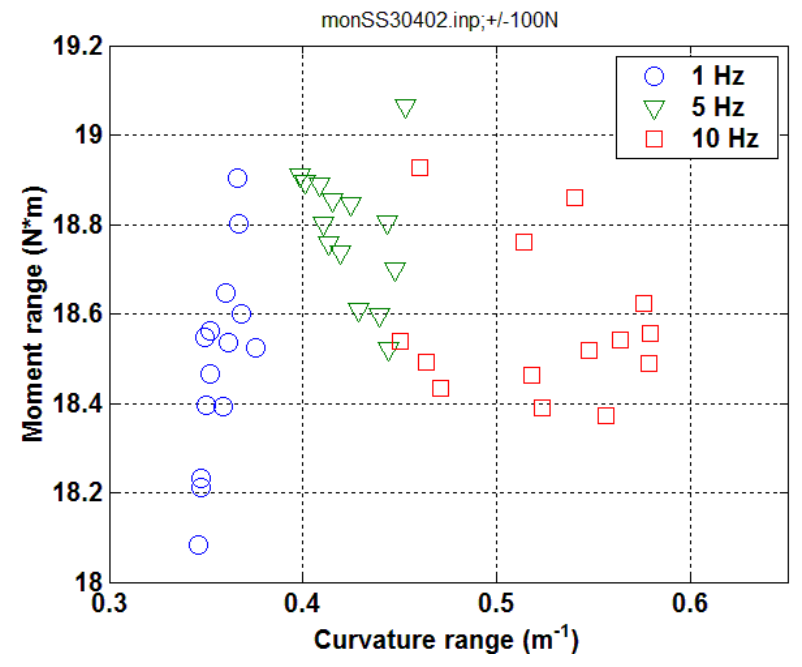

Figure 18 Scatter plot of moment range vs. curvature range based on the first run, SS30402. 


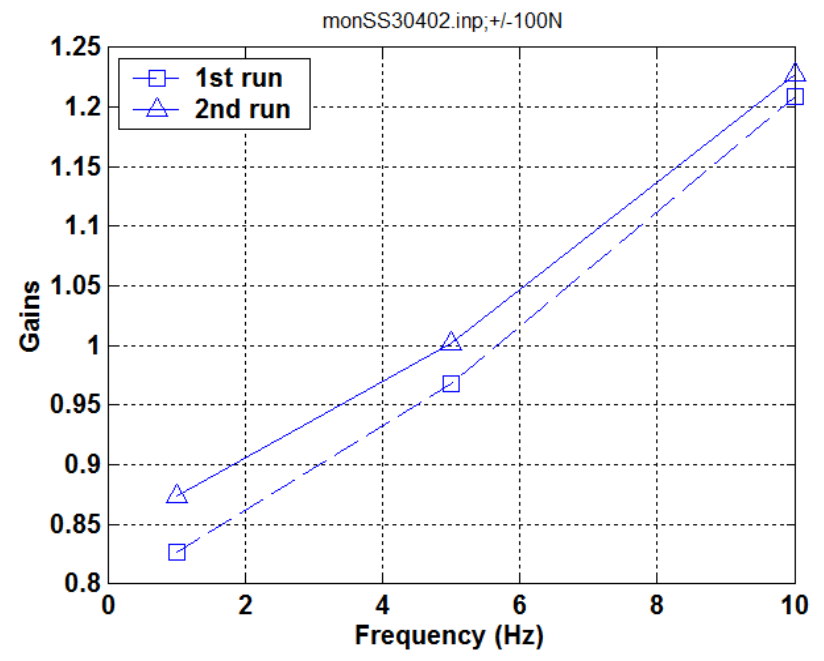

Figure 19 Gain as a function of frequency based on results of SS30402.

\section{Conclusion}

A new CIRFT system was assembled with the same configuration as the first one and to be used as out-of-cell operation. The central panel, alpha plug, and other hot-cell adaptions have not been integrated pending upon further request for hot-cell application.

With the out-of-cell study, it has been observed that:

- Overall, no significant probe contact effect was seen on the curvature response of the rod under test.

- A marginal decrease in chisel-based curvature remains to be investigated.

- No significant effects of test stops and channel resets were observed in both flat and chisel contacts.

- No significant effect of ending control was seen on the curvature response with respect to displacement and load control.

By using DM2 in hot-cell testing as a study case, it has been demonstrated that curvature can be resolved in small amplitude measurement by using the proposed smoothing approach.

It has been shown that, by using a calibration rod with known properties, the dynamic response of the U-frame setup in the target frequency range can be studied. The gain can be defined, but may be depend on the calibration rod used. 


\section{Future Work}

Future work of this project will focus on the hot-cell testing.

1. Replicate dynamic tests of HB Robinson fuel (7.5N-m; 9N-m; $10.0 \mathrm{~N}-\mathrm{m} ; 12.5 \mathrm{~N}-\mathrm{m})$

a. Perform 2-3 hydride reorientation tests under different hoop stress and repeat the tests above [this will involve defueling the ends of several samples, welding on end caps and pressurizing the samples followed by heating the samples to reorient the hydrides].

2. Conduct testing of other available PWR fuel (2 Static tests; 1 dynamic calibration; 5 dynamic tests with 2 or more repeat tests):

a. TMI Low-Sn Zyr-4

b. Surry-2 Zircaloy-4

c. North Anna M5

d. Catawba M5 (MOX)

e. Perform hydride reorientation tests for some selected samples

3. BWR UNF tests

a. Limerick BWR-4 (2 Static tests; 1 dynamic calibration; 5 dynamic tests with 2 or more repeat tests)

b. Perform 2-3 hydride reorientation tests under different hoop stress and repeat the tests above.

4. Conduct CIRFT tests on lower burnup commercial fuel (30 - $40 \mathrm{GWd} / \mathrm{MT}$ ) under the same conditions as the high burnup UNF was tested.

5. Perform 2-3 hydride reorientation tests under different hoop stress conditions

6. Conduct ring compression tests on commercial fuel samples (fueled) at RT and at elevated temperature.

7. Conduct ring compression tests on PNNL and ORNL pre-hydrided, HFIR irradiated test samples (various clad types) at RT and elevated temperature (no surrogate fuel in samples).

8. Conduct ring compression tests on PNNL and ORNL pre-hydrided, HFIR irradiated test samples (various clad types) at RT and elevated temperature WITH surrogate fuel. 
9. Anneal some HBR samples and test to load levels used in previous experiments (nonpressurized tests).

10. Conduct CIRFT tests on HFIR irradiated PNNL/ORNL cladding

a. Conduct tests without annealing samples

i. Un-hydrided

ii. Pre-hydrided

b. Anneal some of the clad samples, conduct CIRFT testing

i. Un-hydrided

ii. Pre-hydrided

11. CIRFT test PNNL and ORNL irradiated/pre-hydrided samples (various clad types) that have had the hydrides reoriented, and perform tests under different hoop stresses.

a. This testing will require end caps to be welded on the samples, rodlet pressurization, heating and controlled cooling of the test samples prior to testing.

12. Test high burnup samples to "equivalent” NCT cycles and loads (peak expected cycles and loads) - test the unbroken samples (including PIE)

a. Conduct tests on PWR fuel

b. Conduct tests on BWR fuel

13. Perform CIRFT tests of defueled clad (limited number of cladding types - differences between clads should be insignificant)

14. Perform CIRFT tests of defueled clad (limited number of cladding types - differences between clads should be insignificant)

15. Test high burnup WE 17x17 to obtain material data values for stiffness, bend failure, and cyclic fatigue failure characteristics

16. Test $17 x 17$ specimens with significant hydride reorientation (then compare the $15 \times 15$ data to the $17 \mathrm{x} 17$ data to have representative material data)

\section{Acknowledgments}

The research was sponsored by DOE Used Fuel Disposition Campaign program under DOE contract DE-AC05-00OR22725 with UT-Battelle, LLC. 


\section{References}

1. J.-A. J. Wang and H. Wang, Progress Letter Report on Reversal Bending Fatigue Testing of Zry-4 Surrogate Rod (Out-of-Cell Fatigue Testing Development-Task 2.4), ORNL/TM2013/297, Oak Ridge National Laboratory, Oak Ridge, Tenn., August 2013.

2. J.-A. J. Wang, H. Wang, B. B. Bevard, R. L. Howard, and M. E. Flanagan, Reversible Bending Fatigue Test System for Investigating Vibration Integrity of Spent Nuclear Fuel During Transportation, PATRAM 2013, DOE/NRC/DOT, San Francisco, Calif., August 18-23, 2013.

3. J.-A. J. Wang, H. Wang, T. Cox, and C. Baldwin, Progress Letter Report on Bending Fatigue Test System Development for Spent Nuclear Fuel Vibration Integrity Study (Outof-Cell Fatigue Testing Development-Task 2.4), ORNL/TM-2013/225, Oak Ridge National Laboratory, Oak Ridge, Tenn., July 2013.

4. H. Wang, J.-A. J. Wang, T. Tan, H. Jiang, T. S. Cox, R. L. Howard, B. B. Bevard, and M. E. Flanagan, "Development of U-frame Bending System for Studying the Vibration Integrity of Spent Nuclear Fuel,” Journal of Nuclear Materials 440, 201-213 (2013).

5. J.-A. J. Wang, H. Wang, B. B. Bevard, R. L. Howard, and M. E. Flanagan, SNF Test System for Bending Stiffness and Vibration Integrity, International High-Level Radioactive Waste Management Conference, Albuquerque, N.M., April 28-May 2, 2013.

6. J.-A. J. Wang, H. Wang, and Ting Tan, An Innovative Dynamic Reversal Bending Fatigue Testing System for Evaluating Spent Nuclear Fuel Rod Vibration Integrity or Other Materials Fatigue Aging Performance, ORNL Invention Disclosure 201102593, DOE S-124,149, April 8, 2011. Patent in review, 13/396,413, February 14, 2012.

7. J.-A. J. Wang, H. Wang, T. Cox, and Y. Yan, Progress Letter Report on U-Frame Test Setup and Bending Fatigue Test for Vibration Integrity Study (Out-of-Cell Fatigue Testing Development-Task 2.3), ORNL/TM-2012/417, Oak Ridge National Laboratory, Oak Ridge, Tenn., August 2012.

8. J.-A. J. Wang, H. Wang, T. Tan, H. Jiang, T. Cox, and Y. Yan, Progress Letter Report on U-Frame Test Setup and Bending Fatigue Test for Vibration Integrity Study (Out-of-Cell Fatigue Testing Development-Task 2.2), ORNL/TM-2011/531, Oak Ridge National Laboratory, Oak Ridge, Tenn., January 2012.

9. J.-A. J. Wang, H. Wang, Y. Yan, R. Howard, and B. Bevard, High Burn-up Spent Fuel Vibration Integrity Study Progress Letter Report (Out-of-Cell Fatigue Testing Development-Task 2.1), ORNL/TM-2010/288, Oak Ridge National Laboratory, Oak Ridge, Tenn., January 2011. 